\title{
Practical genetics: alpha-1-antitrypsin deficiency and the serpinopathies
}

\author{
Damian C Crowther ${ }^{1}$, Didier Belorgey ${ }^{1}$, Elena Miranda ${ }^{1}$, Kerri J Kinghorn ${ }^{1}$, Lynda K Sharp ${ }^{1}$ \\ and David A Lomas*,1
}

${ }^{1}$ Department of Medicine, University of Cambridge, Cambridge Institute for Medical Research, Wellcome Trust/MRC Building, Hills Road, Cambridge CB2 2XY, UK

Alpha-1-antitrypsin ( $\alpha_{1}$-antitrypsin) is the archetypal member of the serine proteinase inhibitor or serpin superfamily. The most common severe deficiency variant is the $Z$ allele, which results in the accumulation of mutant protein within hepatocytes. This 'protein overload' causes neonatal hepatitis, cirrhosis and hepatocellular carcinoma. The lack of circulating plasma $\alpha_{1}$-antitrypsin results in early-onset panlobular emphysema. The mechanism underlying the deficiency of $Z \alpha_{1}$-antitrypsin is due to an aberrant conformational transition within the protein and the formation of chains of polymers that tangle within the secretory pathway of hepatocytes. This mechanism also underlies the plasma deficiency of other members of the serpin superfamily to cause a class of diseases called the serpinopathies. Specifically mutant alleles of antithrombin, C1-inhibitor and $\alpha_{1}$-antichymotrypsin have been reported that favour the spontaneous formation of polymers and the retention of protein within hepatocytes. The consequent lack of plasma antithrombin, C1-inhibitor and $\alpha_{1}$-antichymotrypsin results in thrombosis, angio-oedema and emphysema, respectively. Moreover, the polymerisation of mutants of neuroserpin results in the retention of polymers within neurones to cause the inclusion body dementia, familial encephalopathy with neuroserpin inclusion bodies or FENIB. We review here the genetic and molecular basis and clinical features of $\alpha_{1}$-antitrypsin deficiency, and show how this provides a platform to understand the other serpinopathies.

European Journal of Human Genetics (2004) 12, 167-172. doi:10.1038/sj.ejhg.5201127

Published online 24 December 2003

Keywords: $\alpha_{1}$-antitrypsin; $\alpha_{1}$-antichymotrypsin; antithrombin; C1-inhibitor; neuroserpin; serpins; serpinopathies

Alpha-1-antitrypsin

Gene structure and common mutations

Alpha-1-antitrypsin ( $\alpha_{1}$-antitrypsin) is a 394 amino acid, $52 \mathrm{kDa}$, acute-phase glycoprotein synthesised by the liver and macrophages and present in the plasma at a concentration of $1.5-3.5 \mathrm{~g} / \mathrm{l}$. It functions as an inhibitor of a range of proteolytic enzymes, but its primary role is to inhibit the

*Correspondence: Professor D Lomas, Department of Medicine, University of Cambridge, Cambridge Institute for Medical Research, Wellcome Trust/MRC Building, Hills Road, Cambridge CB2 2XY, UK. Tel: +42 1223 762818; Fax: +42 1223 336827; E-mail: dal16@cam.ac.uk Received 14 July 2003; revised 24 September 2003; accepted 17 October 2003 enzyme neutrophil elastase. $\alpha_{1}$-Antitrypsin is subject to genetic variation resulting from mutations in the $12.2 \mathrm{~kb}$, 7-exon gene at q31-31.2 on chromosome $14 .{ }^{1}$ Over 75 allelic variants have been reported and classified using the protease inhibitor (PI) nomenclature that assesses $\alpha_{1}$-antitrypsin mobility in isoelectric focusing analysis. ${ }^{2}$ Normal $\alpha_{1}$-antitrypsin migrates in the middle $(\mathrm{M})$ and variants are designated $\mathrm{A}-\mathrm{L}$ if they migrate faster than $\mathrm{M}$, and $\mathrm{N}-\mathrm{Z}$ if they migrate more slowly. The most clinically relevant variants are the $S$ (Glu264Val) and Z (Glu342Lys) alleles and the uncommon Null alleles that result from point mutations that introduce premature stop codons. 


\section{Epidemiology}

The greatest frequency of the $\mathrm{S}$ allele is within the Iberian Peninsula and gradually reduces in the direction of South to North and from West to East. ${ }^{3}$ Heterozygotes for the $S$ allele of $\alpha_{1}$-antitrypsin (PI*MS) comprise up to $28 \%$ of Southern Europeans and although they have plasma $\alpha_{1}$ antitrypsin levels that are $80 \%$ of the $\mathrm{M}$ allele, the deficiency is not associated with any clinical sequeale. In contrast, the $\mathrm{Z}$ allele is most common in northwest Europe with frequencies declining from West to East and from North to South. ${ }^{3}$ Approximately $4 \%$ of Northern Europeans are heterozygous for the $\mathrm{Z}$ allele (PI*MZ) with one in 1700 being homozygotes $\left(\mathrm{PI}^{*} \mathrm{Z}\right)$. The $\mathrm{Z}$ allele results in plasma levels that are $10-15 \%$ of the $M$ allele. It causes both neonatal and adult liver disease and adult-onset emphysema.

\section{Molecular mechanism of $\alpha_{1}$-antitrypsin deficiency} $\alpha_{1}$-Antitrypsin functions by presenting its reactive centre methionine residue on an exposed loop of the molecule such that it forms an ideal substrate for the enzyme neutrophil elastase. Following docking, the enzyme is translocated over $70 \AA$ from the upper to the lower pole of the protein where it is crushed and inactivated. ${ }^{4-6}$ This is achieved by the reactive centre loop inserting in $\beta$-sheet A (Figure 1a). The $\mathrm{Z}$ mutation (Glu342Lys) distorts the relationship between the reactive centre loop and $\beta$-sheet $\mathrm{A}$ (Figure 1b). The consequent perturbation in structure allows the reactive centre loop of one $\alpha_{1}$-molecule to lock into the A sheet of a second to form a dimer, which then extends to form chains of loop-sheet polymers. ${ }^{7,8}$ These polymers are then degraded ${ }^{9}$ or accumulate within the endoplasmic reticulum of hepatocytes to form the PASpositive inclusions that are the hallmark of $\mathrm{Z} \alpha_{1}$-antitrypsin liver disease (Figure 2). The $S_{\text {iiyama }}$ (Ser53Phe) and $\mathrm{M}_{\text {malton }}$ (52 phenylalanine deletion) variants are located in the shutter domain of the molecule (Figure $1 b$ ) and also favour the rapid formation of polymers. $S \alpha_{1}$-antitrypsin (Glu264Val) and the rare I variant (Arg39Cys) similarly result in polymersation, but at a much slower rate than the $\mathrm{Z}, \mathrm{S}_{\text {iiyama }}$ or $\mathrm{M}_{\text {malton }}$ alleles. Therefore, these variants do not accumulate in the liver and cause only mild plasma deficiency. It should be stressed that the liver disease associated with $\mathrm{Z} \alpha_{1}$-antitrypsin deficiency is not due to plasma deficiency but is secondary to protein overload. Some confirmation is provided by the Null alleles that are unable to polymerise and do not appear to cause liver disease. ${ }^{2}$ They do however predispose to the development of emphysema.

The emphysema that is associated with $\mathrm{PI}^{*} \mathrm{Z} \alpha_{1}$-antitrypsin deficiency is intimately linked with the lack of proteinase inhibitor within the lung that is available to bind to, and inactivate, neutrophil elastase. The single most important factor in determining the age of onset and progression of emphysema in these individuals is a
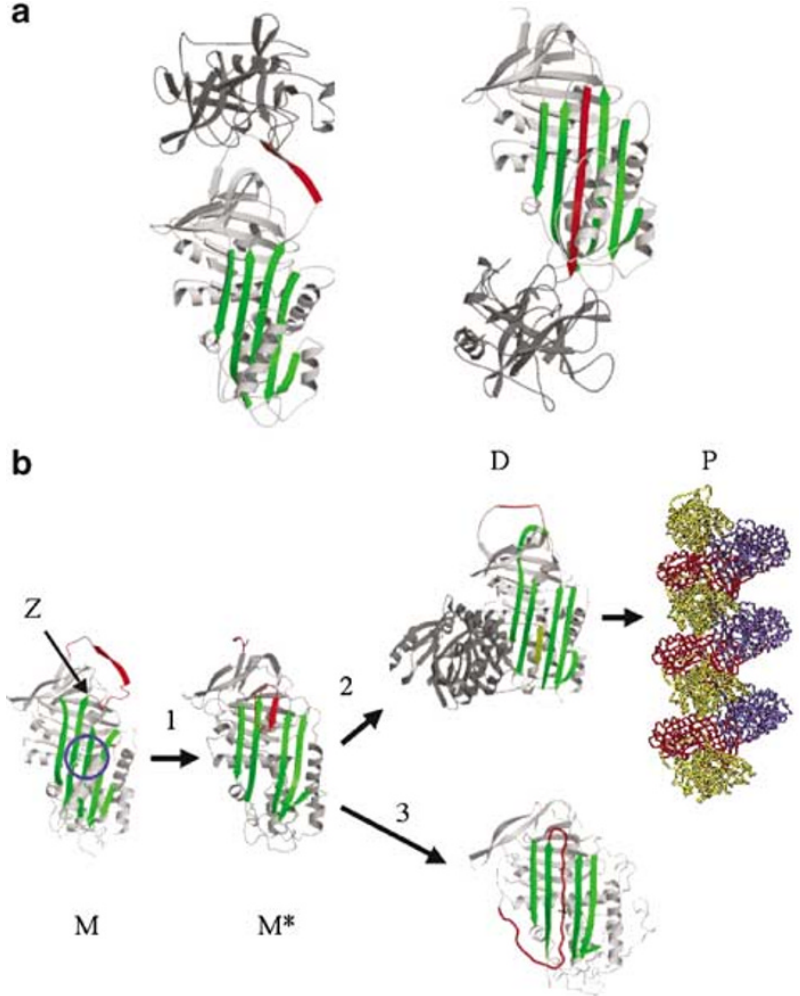

L

Figure 1 (a) Inhibition of neutrophil elastase by $\alpha_{1}$-antitrypsin. Following docking (left) the neutrophil elastase (grey) is inactivated by movement from the upper to the lower pole of the protein (right). This is associated with insertion of the reactive loop (red) as an extra strand into $\beta$-sheet A (green). Reproduced from Lomas and Carrell ${ }^{5}$ with permission. (b) The structure of $\alpha_{1}$-antitrypsin is centred on $\beta$-sheet $A$ (green) and the mobile reactive centre loop (red). Polymer formation results from the $Z$ variant of $\alpha_{1}$ antitrypsin (Glu342Lys at $\mathrm{P}_{17}$; arrowed) or mutations in the shutter domain (blue circle) that open $\beta$-sheet $A$ to favour partial loop insertion (step 1) and the formation of an unstable intermediate $\left(\mathrm{M}^{*}\right)$. The patent $\beta$-sheet $\mathrm{A}$ can either accept the loop of another molecule (step 2) to form a dimer (D), which then extends into polymers (P). A small proportion of the unstable serpin molecules can accept their own loop (step 3) to form an inactive, thermostable, latent conformation (L). The individual molecules of $\alpha_{1}$-antitrypsin within the polymer are coloured red, yellow and blue. Reproduced from Gooptu et $a \beta^{30}$ with permission.

smoking. ${ }^{10}$ However, there is considerable variability in the severity of lung disease in smokers with the same PI* Z genotype. ${ }^{11}$ More recently, it has been recognised that other pathways contribute to the emphysema associated with PI* $Z \alpha_{1}$-antitrypsin deficiency: (i) The $\mathrm{Z} \alpha_{1}$-antitrypsin that escapes from the liver and that which is produced locally in the lung is five-fold less effective at inhibiting neutrophil elastase than normal $\mathrm{M} \alpha_{1}$-antitrypsin. ${ }^{12}$ (ii) $\mathrm{Z}$ $\alpha_{1}$-antitrypsin spontaneously forms polymers within the 

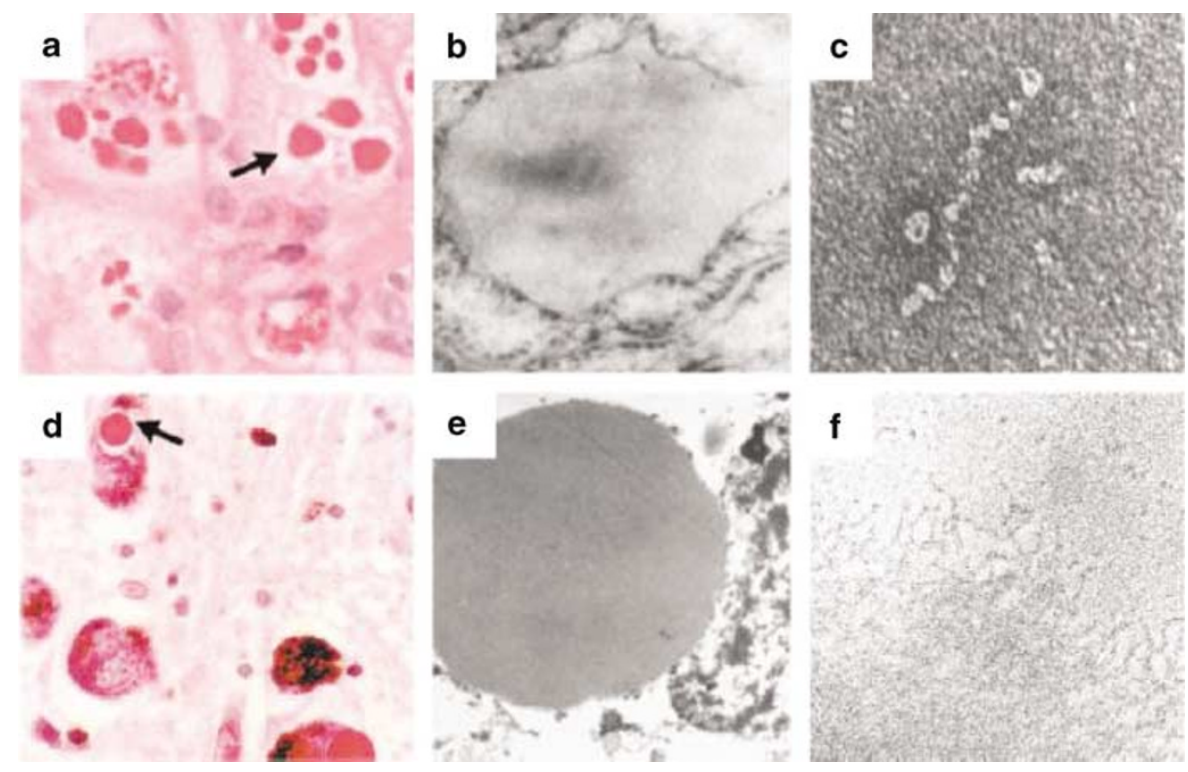

Figure $2 \mathrm{Z} \alpha_{1}$-antitrypsin is retained within hepatocytes as intracellular inclusions. These inclusions are PAS positive and diastase resistant (a, arrowed) and are associated with neonatal hepatitis and hepatocellular carcinoma (b). Electron micrograph of an hepatocyte from the liver of a patient with $\mathrm{PI}^{*} \mathrm{Z} \alpha_{1}$-antitrypsin deficiency shows the accumulation of $\alpha_{1}$ antitrypsin within the rough endoplasmic reticulum. These inclusions are composed of chains of $\alpha_{1}$-antitrypsin polymers shown here from the plasma of a PI*S iiyama $\alpha_{1}$-antitrypsin homozygote (c) and from the liver of a PI*Z $\alpha_{1}$-antitrypsin homozygote (f). Similar mutations in $\alpha_{1}$-antitrypsin deficiency and neuroserpin encephalopathy result in similar intracellular inclusions of $\alpha_{1}$-antitrypsin and neuroserpin. They are shown here in hepatocytes and neurons with PAS staining (a and $\mathbf{d}$, respectively) and as endoplasmic aggregates of the abnormal proteins on electron microscopy (b and e, respectively). Electron microscopy confirms that the abnormal neuroserpin forms bead-like polymers and entangled polymeric aggregates identical to those shown here with $Z \alpha_{1}$-antitrypsin (c and f) (magnification left to right: $\times 200, \times 20000, \times 220000$ ). Figure reproduced from Carrell and Lomas ${ }^{4}$ with permission.

lung. ${ }^{13}$ This conformational transition inactivates $\alpha_{1}$-antitrypsin as a proteinase inhibitor, thereby further reducing the already depleted levels of $\alpha_{1}$-antitrypsin that are available to protect the alveoli. (iii) Intrapulmonary polymers are chemotactic for human neutrophils in vitro, ${ }^{14}$ and this may explain the finding that patients with $\mathrm{Z} \alpha_{1^{-}}$ antitrypsin deficiency have an excess number of neutrophils in bronchoalveolar lavage ${ }^{15}$ and in tissue sections of lung parenchyma. ${ }^{6}$ The relative contribution of each of these pathways to lung damage in any given patient is unknown.

\section{Clinical syndromes}

The liver disease associated with the PI* $Z$ allele of $\alpha_{1}$-antitrypsin results from abnormal $Z \alpha_{1}$-antitrypsin accumulating within the endoplasmic reticulum of hepatocytes. The accumulation of abnormal protein starts in utero and is characterised by the accumulation of diastase-resistant, periodic acid-Schiff-positive inclusions of $\alpha_{1}$-antitrypsin in the periportal cells (Figure 2). In all, $73 \%$ of PI*Z $\alpha_{1}$-antitrypsin homozygote infants have a raised serum alanine aminotransferase in the first year of life, but in only $15 \%$ of cases is it still abnormal by 12 years of age. ${ }^{16}$ Similarly, serum bilirubin is raised in $11 \%$ of $\mathrm{PI}^{\star} \mathrm{Z}$ infants in the first 2-4 months but falls to normal by 6 months of age. One in 10 infants develops cholestatic jaundice and $6 \%$ develop clinical evidence of liver disease without jaundice. These symptoms usually resolve by the second year of life, but approximately $15 \%$ of patients with cholestatic jaundice progress to juvenile cirrhosis. The overall risk of death from liver disease in $\mathrm{PI}^{\star} \mathrm{Z}$ children during childhood is $2-3 \%$ with boys being at more risk than girls. The factors that cause the progression of liver disease in some children, but not others, are unknown but may relate to intercurrent infection/inflammation and/or other genetic factors.

All adults with the PI*Z allele of $\alpha_{1}$-antitrypsin have slowly progressive hepatic damage that is often subclinical and only evident as a minor degree of portal fibrosis. However, up to $50 \%$ of PI*Z $\alpha_{1}$-antitrypsin homozygotes present with clinically evident cirrhosis and occasionally with hepatocellular carcinoma. ${ }^{17}$ The accumulation of $\alpha_{1}$-antitrypsin within hepatocytes in association with severe plasma deficiency is also seen with two other rare mutations: the $\mathrm{PI}^{*} \mathrm{~S}_{\text {iiyama }}$ variant (Ser53Phe) that is the most common cause of $\alpha_{1}$-antitrypsin deficiency in Japan and $\mathrm{PI}{ }^{*} \mathrm{M}_{\text {malton }}$ (52 phenylalanine deletion) that is the most common cause of $\alpha_{1}$-antitrypsin deficiency in 
Sardinia. Both of these alleles probably also cause liver disease, but there is currently insufficient evidence to state conclusively that this is the case. The risk of liver disease in individuals who are heterozygous for the $\mathrm{Z}$ allele (ie PI*MZ) is uncertain.

The respiratory disease associated with severe $\alpha_{1}$-antitrypsin deficiency usually presents with increasing dyspnoea with cor pulmonale and polycythaemia occurring late in the course of the disease. Chest radiographs typically show bilateral basal emphysema with paucity and pruning of the basal pulmonary vessels. Upper lobe vascularisation is relatively normal. Ventilation perfusion radioisotope scans and angiography also show abnormalities with a lower zone distribution. High-resolution CT scans with 1-2 mm collimation are the most accurate method of assessing the distribution of panlobular emphysema and for monitoring progress of the pulmonary disease, ${ }^{18}$ although this currently has little clinical value. Lung function tests are typical for emphysema with a reduced $\mathrm{FEV}_{1} / \mathrm{FVC}$ ratio, gas trapping (raised ratio of residual volume to total lung capacity) and low gas transfer factor. The onset of respiratory disease can be delayed to the sixth decade in non-smokers with $\mathrm{PI}^{*} \mathrm{Z} \alpha_{1}$-antitrypsin deficiency, and these individuals often have a normal lifespan. ${ }^{19}$ Lung disease is characteristically seen in $\mathrm{PI}{ }^{*} \mathrm{Z} \alpha_{1^{-}}$ antitrypsin homozygotes, but $\mathrm{PI}{ }^{\star} \mathrm{MZ}$ individuals also have a slightly greater risk of emphysema if they smoke.

\section{Diagnosis}

$\alpha_{1}$-Antitrypsin deficiency is usually suspected in infants with neonatal hepatitis, cholestatic jaundice or cirrhosis, or adults with cirrhosis and/or hepatocellular carcinoma. It presents in the adult population as emphysema that characteristically affects the bases of the lungs. $\alpha_{1}$-Antitrypsin deficiency should also be considered in patients with Wegener's granulomatosis and panniculitis. $\alpha_{1}$-Antitrypsin alleles are codominantly expressed with each allele contributing to the plasma level of protein. Thus each of the deficiency alleles results in a characteristic decrease in the plasma concentration of $\alpha_{1}$-antitrypsin; the $S$ variant forms $60 \%$ of the normal $M$ concentration and the $\mathrm{Z}$ variant $10-15 \%$. A combination of alleles also has predictable effects, the PI*MZ heterozygote has a plasma level of $\alpha_{1}$-antitrypsin of $60 \%$ (50\% from the normal $\mathrm{M}$ allele and $10 \%$ from the $\mathrm{Z}$ allele), the PI*MS heterozygote $80 \%$ and the PI*SZ heterozygote $40 \%$. The measurement of plasma levels alone does have limitations as the concentration of protein rises during the acute-phase response and this can mask a partial deficiency of $\alpha_{1}$-antitrypsin. However, the plasma level never reaches the normal range in the PI*Z $\alpha_{1}$-antitrypsin homozygote. The diagnosis of abnormal alleles is made by assessing the mobility of $\alpha_{1}$ antitrypsin in isoelectric focusing analysis. If this is ambiguous then the presence of the $\mathrm{Z}$ or other alleles can be confirmed by genotype analysis.

\section{Animal models}

Mice have been generated that overexpress the $M$ and $\mathrm{Z}$ alleles of $\alpha_{1}$-antitrypsin. ${ }^{20-22}$ They have a variable severity of liver disease. While there are good models for smoking-related lung damage there is, as yet, no good mouse model for the pulmonary emphysema associated with $\alpha_{1}$-antitrypsin deficiency. Finally, we have recently reported a Drosophila model of serpin polymerisation. ${ }^{23}$ The addition of the $\mathrm{Z}$ mutation (Glu342Lys) to the serpin necrotic causes a temperature-dependent loss of function phenotype in association with the formation of polymers. The utility of the fly as a model of human disease requires further investigation.

\section{Treatment}

The treatment of $\alpha_{1}$-antitrypsin deficiency depends largely on the avoidance of stimuli causing repeated pulmonary inflammation - primarily smoking. Patients with $\alpha_{1}$-antitrypsin deficiency-related emphysema should receive conventional therapy with trials of bronchodilators, inhaled corticosteroids and, where appropriate, assessment for long-term oxygen therapy and single lung transplantation. The role of lung volume reduction surgery in this group is unclear as the lung disease is basal rather than apical and resections of this region are technically more difficult. Thus lung volume reduction surgery should not be offered routinely in patients with $\alpha_{1}$-antitrypsin deficiency until further information is available.

The lung disease results from a deficiency in the antielastase screen. This may be rectified biochemically with intravenous infusions of $\alpha_{1}$-antitrypsin or by giving the protein in a nebulised formulation. Registry data suggest that intravenous replacement therapy is of benefit in slowing the rate of decline in lung function, ${ }^{24}$ but the only randomised-controlled trial failed to show a statistically significant benefit as it lacked sufficient power. ${ }^{18}$ It is estimated that over 500 individuals with $\alpha_{1}$-antitrypsin deficiency are required to have sufficient power to show that intravenous infusions of $\alpha_{1}$-antitrypsin slow the rate of decline in lung function. ${ }^{18}$ Although $\alpha_{1}$-antitrypsin replacement therapy is widely used in North America, it is currently not available in many European countries, including the UK.

$P{ }^{*} Z$ homozygotes should be monitored for the persistence of hyperbilirubinaemia as this, along with deteriorating results of coagulation studies, can indicate worsening liver function and may prompt consideration of liver transplantation. Parents with a child with severe $\mathrm{Z} \alpha_{1}$-antitrypsin liver disease may require genetic counselling. The likelihood of similar severe liver damage in a subsequent $\mathrm{PI}^{\star} \mathrm{Z}$ homozygote sibling is approximately $20 \% .^{25}$ 


\section{Screening}

Population screening can be undertaken by isoelectric focusing. However, the only current therapeutic intervention is to advise the $\mathrm{PI}^{\star} \mathrm{Z} \alpha_{1}$-antitrypsin homozygote against smoking. The follow-up of $127 \mathrm{PI}{ }^{*} \mathrm{Z} \alpha_{1}$-antitrypsin homozygotes from birth demonstrated a $50 \%$ reduction in the prevalence of smoking if an individual knew they had $\alpha_{1}$-antitrypsin deficiency. The prevalence of smoking in the Western world is currently approximately $30 \%$. Thus, approximately 12000 individuals would have to be screened to identify one PI* $Z$ homozygote who would abstain from smoking, but who would have started to smoke had (s)he not been screened. This is currently not cost-effective.

\section{Other serpinopathies}

$\alpha_{1}$-Antitrypsin is the archetypal member of the serine proteinase inhibitor or serpin superfamily. This family includes members such as $\alpha_{1}$-antichymotrypsin, C1 inhibitor, antithrombin and plasminogen activator inhibitor-1, which play an important role in the control of proteinases involved in the inflammatory, complement, coagulation and fibrinolytic cascades, respectively. ${ }^{26}$ The family is characterised by more than $30 \%$ sequence homology with $\alpha_{1}$-antitrypsin and conservation of tertiary structure. Consequently, physiological and pathological processes that affect one member may be extrapolated to another. The phenomenon of loop-sheet polymerisation is not restricted to $\alpha_{1}$-antitrypsin and has now been reported in mutants of other members of the serpin superfamily to cause disease (the serpinopathies). Mutants of C1-inhibitor (Phe52Ser, Pro54Leu, Ala349Thr, Val366Met, Phe370Ser, Pro391Ser), antithrombin (Pro54Thr, Asn158Asp) and $\alpha_{1}$-antichymotrypsin (Leu55Pro, Pro228Ala) can also destabilise the protein architecture to form inactive polymers that are retained within hepatocytes. The associated plasma deficiency results in angio-oedema, thrombosis and chronic obstructive pulmonary disease, respectively (see, Carrell and Lomas $^{4}$, Lomas and Carrell ${ }^{5}$ and Lomas and Mahadeva $^{6}$, for reviews). The process of polymerisation is perhaps most strikingly displayed in the inclusion body dementia, familial encephalopathy with neuroserpin inclusion bodies (FENIB). ${ }^{27}$ We have shown that this dementia is caused in heterozygotes by a mutation in neuroserpin (Ser49Pro) that is homologous to that causing liver cirrhosis in $\alpha_{1}$-antitrypsin deficiency. ${ }^{27}$ Moreover, both the liver cirrhosis and the neurodegenerative disease have an identical pattern of intracellular polymerisation and inclusion body formation (Figure 2). Further kindreds with polymerogenic neuroserpin mutations have been described (Ser52Arg, His338Arg, Gly392Glu), and it is becoming clear that there is a direct relationship between the magnitude of intracellular accumulation of neuroserpin and the severity of the clinical syndrome. ${ }^{28}$ This is supported by recent work demonstrating that one of the neuroserpin mutants that causes FENIB (Ser49Pro), polymerises up to 13 -fold faster than wild-type protein. ${ }^{29}$ These data provide strong support for the role of aberrant neuroserpin polymerisation in the pathogenesis of FENIB.

Thus, the polymerisation of $\alpha_{1}$-antitrypsin has provided a paradigm for a new class of conditions, the serpinopathies, that result from a similar molecular mechanism. Strategies to block polymerisation would provide effective therapy for a wide range of clinical syndromes.

\section{References}

1 Billingsley GD, Walter MA, Hammond GL, Cox DW: Physical mapping of four serpin genes: $\alpha_{1}$-antitrypsin, $\alpha_{1}$-antichymotrypsin, corticosteroid-binding globulin, and protein $\mathrm{C}$ inhibitor, within a $280 \mathrm{~kb}$ region on chromosome $14 \mathrm{q} 31.1$. Am J Hum Genet 1993; 52: 343-353.

2 Brantly M, Nukiwa T, Crystal RG: Molecular basis of alpha-1antitrypsin deficiency. Am J Med 1988; 84 (Suppl 6A): 13-31.

3 Blanco I, Fernández E, Bustillo EF: Alpha-1-antitrypsin PI phenotypes $\mathrm{S}$ and $\mathrm{Z}$ in Europe: an analysis of the published surveys. Clin Genet 2001; 60: 31-41.

4 Carrell RW, Lomas DA: Alpha ${ }_{1}$-antitrypsin deficiency: a model for conformational diseases. N Engl J Med 2002; 346: 45-53.

5 Lomas DA, Carrell RW: Serpinopathies and the conformational dementias. Nat Rev Genet 2002; 3: 759-768.

6 Lomas DA, Mahadeva R: Alpha-1-antitrypsin polymerisation and the serpinopathies: pathobiology and prospects for therapy. J Clin Invest 2002; 110: 1585-1590.

7 Lomas DA, Evans DL, Finch JT, Carrell RW: The mechanism of $\mathrm{Z} \alpha_{1}$-antitrypsin accumulation in the liver. Nature 1992; 357: 605-607.

8 Janciauskiene S, Dominaitiene R, Sternby NH, Piitulainen E, Eriksson S: Detection of circulating and endothelial cell polymers of $\mathrm{Z}$ and wildtype alpha-1-antitrypsin by a monoclonal antibody. J Biol Chem 2002; 277: 26540-26546.

$9 \mathrm{Wu}$ Y, Swulius MT, Moremen KW, Sifers RN: Elucidation of the molecular logic by which misfolded $\alpha_{1}$-antitrypsin is preferentially selected for degradation. Proc Natl Acad Sci USA 2003; 100: 8229-8234.

10 Piitulainen E, Eriksson S: Decline in FEV1 related to smoking status in individuals with severe alpha1-antitrypsin deficiency. Eur Resp J 1999; 13: 247-251.

11 Silverman EK, Province MA, Campbell EJ, Pierce JA, Rao DC: Biochemical intermediates in $\alpha_{1}$-antitrypsin deficiency: residual family resemblance for total $\alpha_{1}$-antitrypsin, oxidised $\alpha_{1^{-}}$ antitrypsin, and immunoglobulin $\mathrm{E}$ after adjustment for the effect of the Pi locus. Genet Epidemiol 1989; 7: 137-149.

12 Ogushi F, Fells GA, Hubbard RC, Straus SD, Crystal RG: Z-type $\alpha_{1}$-antitrypsin is less competent than M1-type $\alpha_{1}$-antitrypsin as an inhibitor of neutrophil elastase. J Clin Invest 1987; 80: 1366-1374.

13 Elliott PR, Bilton D, Lomas DA: Lung polymers in $\mathrm{Z} \alpha_{1}$-antitrypsin related emphysema. Am J Resp Cell Mol Biol 1998; 18: 670-674.

14 Parmar JS, Mahadeva R, Reed BJ et al: Polymers of $\alpha_{1}$-antitrypsin are chemotactic for human neutrophils: a new paradigm for the pathogenesis of emphysema. Am J Resp Cell Mol Biol 2002; 26: $723-730$.

15 Morrison HM, Kramps JA, Burnett D, Stockley RA: Lung lavage fluid from patients with $\alpha_{1}$-proteinase inhibitor deficiency or chronic obstructive bronchitis: anti-elastase function and cell profile. Clin Sci 1987; 72: 373-381.

16 Sveger T: The natural history of liver disease in $\alpha_{1}$-antitrypsin deficient children. Acta Paediatr Scand 1988; 77: 847-851.

17 Eriksson S, Carlson J, Velez R: Risk of cirrhosis and primary liver cancer in alpha ${ }_{1}$-antitrypsin deficiency. $N$ Engl J Med 1986; 314: 736-739. 
18 Dirksen A, Dijkman JH, Madsen F et al: A randomised clinical trial of $\alpha_{1}$-antitrypsin augmentation therapy. Am J Resp Crit Care Med 1999; 160: 1468-1472.

19 Seersholm N, Kok-Jensen A: Clinical features and prognosis of life time non-smokers with severe $\alpha_{1}$-antitrypsin deficiency. Thorax 1998; 53: 265-268.

20 Dycaico MJ, Grant SGN, Felts K et al: Neonatal hepatitis induced by $\alpha_{1}$-antitrypsin: a transgenic mouse model. Science $1988 ; 242$ : 1409-1412.

21 Carlson JA, Barton Rogers B, Sifers RN et al: Accumulation of PiZ $\alpha_{1}$-antitrypsin causes liver damage in transgenic mice. J Clin Invest 1989; 83: 1183-1190.

22 Ali R, Perfumo S, della Rocca C et al: Evaluation of a transgenic mouse model for alpha-1-antitrypsin (AAT) related liver disease. Ann Hum Genet 1994; 58: 305-320.

23 Green C, Brown G, Dafforn TR, Morley T, Lomas DA, Gubb D: Mutations in the Drosophila serpin necrotic mirror diseaseassociated mutations of human serpins. Development 2003; 130: $1473-1478$.

24 The alpha-1-antitrypsin deficiency Registry Study Group: Survival and $\mathrm{FEV}_{1}$ decline in individuals with severe deficiency of $\alpha_{1}$-antitrypsin. Am J Resp Crit Care Med 1998; 158: 49-59.
25 Ibarguen E, Gross CR, Savik SK, Sharp HL: Liver disease in alpha1-antitrypsin deficiency: prognostic indicators. J Pediatr 1990; 117: $864-870$.

26 Silverman GA, Bird PI, Carrell RW et al: The serpins are an expanding superfamily of structurally similar but functionally diverse proteins. Evolution, novel functions, mechanism of inhibition and a revised nomenclature. J Biol Chem 2001; 276: 33293-33296.

27 Davis RL, Shrimpton AE, Holohan PD et al: Familial dementia caused by polymerisation of mutant neuroserpin. Nature 1999; 401: $376-379$.

28 Davis RL, Shrimpton AE, Carrell RW et al: Association between conformational mutations in neuroserpin and onset and severity of dementia. Lancet 2002; 359: 2242-2247.

29 Belorgey D, Crowther DC, Mahadeva R, Lomas DA: Mutant neuroserpin (Ser49Pro) that causes the familial dementia FENIB is a poor proteinase inhibitor and readily forms polymers in vitro. J Biol Chem 2002; 277: 17367-17373.

30 Gooptu B, Hazes B, Chang W-SW et al: Inactive conformation of the serpin $\alpha 1$-antichymotrypsin indicates two stage insertion of the reactive loop; implications for inhibitory function and conformational disease. Proc Natl Acad Sci USA 2000; 97: 67-72. 